\title{
An Executive MBA Program in Business Engineering: A Curriculum Focusing on Change
}

\author{
Robert Winter \\ University of St. Gallen, Switzerland
}

Robert.Winter@unisg.ch

\section{Executive Summary}

In many industries, business structures that were considered as stable over many decades have started to change rapidly, leading to a large bundle of complex, often radical and dramatic transformation needs in affected organizations. For example, due to deregulation, outsourcing, usage of electronic channels and particularly business networking, retail banking has been transformed more during the last five years than in the whole generation before.

Designing and implementing changes of such complexity and scale require cross-disciplinary qualifications. Successful transformations must consistently comprise business strategy, business processes, information systems and even corporate culture. Neither general management skills nor technical (information systems) skills nor leadership skills alone are sufficient to assess the potential of IT innovations, to (re-)design business architectures and business models, to (re-)design appropriate business processes and metrics, to (re-)design appropriate information systems, and to provide leadership in a transforming organization.

Most Executive MBA programs, however, are pursuing a traditional, disciplinary business administration approach rather than integrating the various disciplines relevant to change management. While ge neral management skills are needed for strategic vision and organizational development, specific management skills are needed for process redesign, and technical skills are necessary to assess business potentials of IT innovations and to manage the development of appropriate information systems support. Finally, 'soft' skills are a prerequisite for successful leadership and change management in transforming organizations.

Starting in the mid 1990s, faculty at the University of St. Gallen developed Business Engineering, a cross-disciplinary, model and method based approach to holistic transformation management. As a consequence, a respective Executive MBA program has been developed to integrate knowledge from all relevant disciplines. This paper outlines theoretical foundations and describes the current curriculum as well as experience from the first six classes and future plans.

Keywords : transformation, executive MBA, business engineering, curriculum development, change

Material published as part of this journal, either on-line or in print, is copyrighted by the publisher of the Journal of Information Technology Education. Permission to make digital or paper copy of part or all of these works for personal or classroom use is granted without fee provided that the copies are not made or distributed for profit or commercial advantage AND that copies 1) bear this notice in full and 2) give the full citation on the first page. It is permissible to abstract these works so long as credit is given. To copy in all other cases or to republish or to post on a server or to redistribute to lists requires specific permission and payment of a fee. Contact Editor@ JITE.org to request redistribution permission.

\section{Introduction}

In many industries, business structures considered as stable over many decades have started to change rapidly, leading to a large bundle of complex, often radical and dramatic transformation needs in affected organizations. During the last decade, as an example, industry structure in financial services has been shifting from a traditional, production-oriented approach (universal banks vs. insurance companies) over a short 'total finance' consolidation phase to a 


\section{An Executive MBA Program in Business Engineering}

component-based approach where few large, efficient 'factories', many customer-oriented distribution units and many specialized services understand themselves as nodes of an open, flexible business ne twork. In contrast to the consequences of change that are equally covering strategy, processes, leadership, company culture, and information systems (Kelly, 1998), most of the triggers and enablers of change can be located in IT (Evans, Wurster, 1999). Although deregulation and globalization also play an important role, the transformation in the financial services example has been largely enabled by new 'personal' devices that allow customer multi-channel access to financial services anytime and anywhere, by new standardized software packages, by automatic clearing and settlement mechanisms, by powerful data integration and data mining solutions, etc. The emergence of a new layer of service intermediaries is enabled by common access to the Internet and a growing independence of services from physical restrictions that result from paper-based 'production' processes and non-electronic, location-based distribution channels (Hagel, Singer, 1999). Business networking and value chain optimization are enabled by new standardized software packages and particularly by the development of business-oriented negotiation, processing and communication standards (Österle, Fleisch, Alt, 2000).

The management discipline faces massive challenges. Entirely new business models are enabled, while many traditional business models become obsolete. Moreover, integration and automation require a radical redesign of internal processes (Davenport, 1993). Managing alliances, distributed process management, and application integration are recent entries on nearly every top management agenda (Österle, Fleisch, Alt, 2000). In addition, an in-depth understanding of IT innovations is imperative to assess potential business potentials, and soft skills are needed to align company culture with industry transformation, to influence corporate policy-making, and to implement change.

Universities seem not well prepared to 'educate' transformation skills. Like undergraduate programs, most MBA programs focus on traditional, disciplinary knowledge (e.g. marketing, accounting / finance, human resources, operations management, and information systems), although complex transformations require cross-disciplinary skills. Even at renowned business schools, integrated, cross-disciplinary programs focusing on change are hard to find (Team Denzler, 2002). If they exist at all, 'change' programs often are restricted to soft factors and exclude technology issues. 'Techno' MBA programs, on the other hand, focus on technical issues (e.g. communication systems and networks, management information systems, information management, systems development - even programming), and thereby often ignore soft skills. We were not able to identify university programs that offer coverage over the complete range of topics from the potential assessment of IT innovations to strategy making and from process management and systems development to soft factors.

Instead of assembling a new MBA program from existing courses, we chose to first develop a conceptual foundation that tries to integrate these components based on a common vision and a common set of methods and models. Parallel to the 'Enterprise Engineer' approach by Martin (1995), Business Engineering was been proposed initially in the mid 1990s as a holistic methodology for the conceptualization, design, and implementation of IT-enabled business transformation. 'Holistic' means that methodology support is not restricted to information systems development, but that issues like corporate strategy-making, quality management and organizational development as well as organizational psychology are incorporated (Österle, 1995). In addition, a holistic approach requires covering not only technical aspects, but also cultural and political issues that are crucial for the successful implementation of change. Business Engineers must apply technical competencies as well as social skills to envision, design, communicate, lead and implement change projects.

In this paper, we describe the Executive MBA in Business Engineering program that is intended to qualify professionals for all aspects of business transformation. As a conceptual foundation of this program, the Business Engineering approach is described in the next section. The layout and curriculum of the program are described in the third section. A summary of experience from the first four completed and another two running classes concludes the paper in the fourth section. 


\section{Business Engineering}

Business Engineering integrates methods from the following fields:

- technology and innovation management,

- strategic planning,

- systems engineering,

- total quality management, and

- organizational design.

Due to their focus on business or technology, respectively, general managers or systems engineers are not able to holistically conceptualize and manage large transformation projects. Business engineers should have skills 'from both worlds', enabling them to assess business potentials of IT innovations, create strategic visions, analyze and redesign business processes, plan and control transformation projects, and get people actively involved in change processes (Martin, 1995).

Figure 1 illustrates the relationships between transformation, IT, and Business Engineering. Traditional general management know- how is needed to run traditional companies. Various types of IT innovations (as well as other change triggers like deregulation) lead to new business models and to the transformation of existing companies. The core of the Business Engineering methodology is a set of methods and models for transformation management. In addition, new business models and business architectures as well as new business processes and new information systems architectures are provided to envision the utilization of IT innovations.

The overall Business Engineering process (Österle, Winter, 2000) is illustrated by Figure 2. As described above, the transformation is triggered by IT innovations and other enablers that need to be monitored and assessed with regard to new business opportunities. The transformation process covers a business strategy, a business process, and finally an information systems level in a top-down way. Parallel to

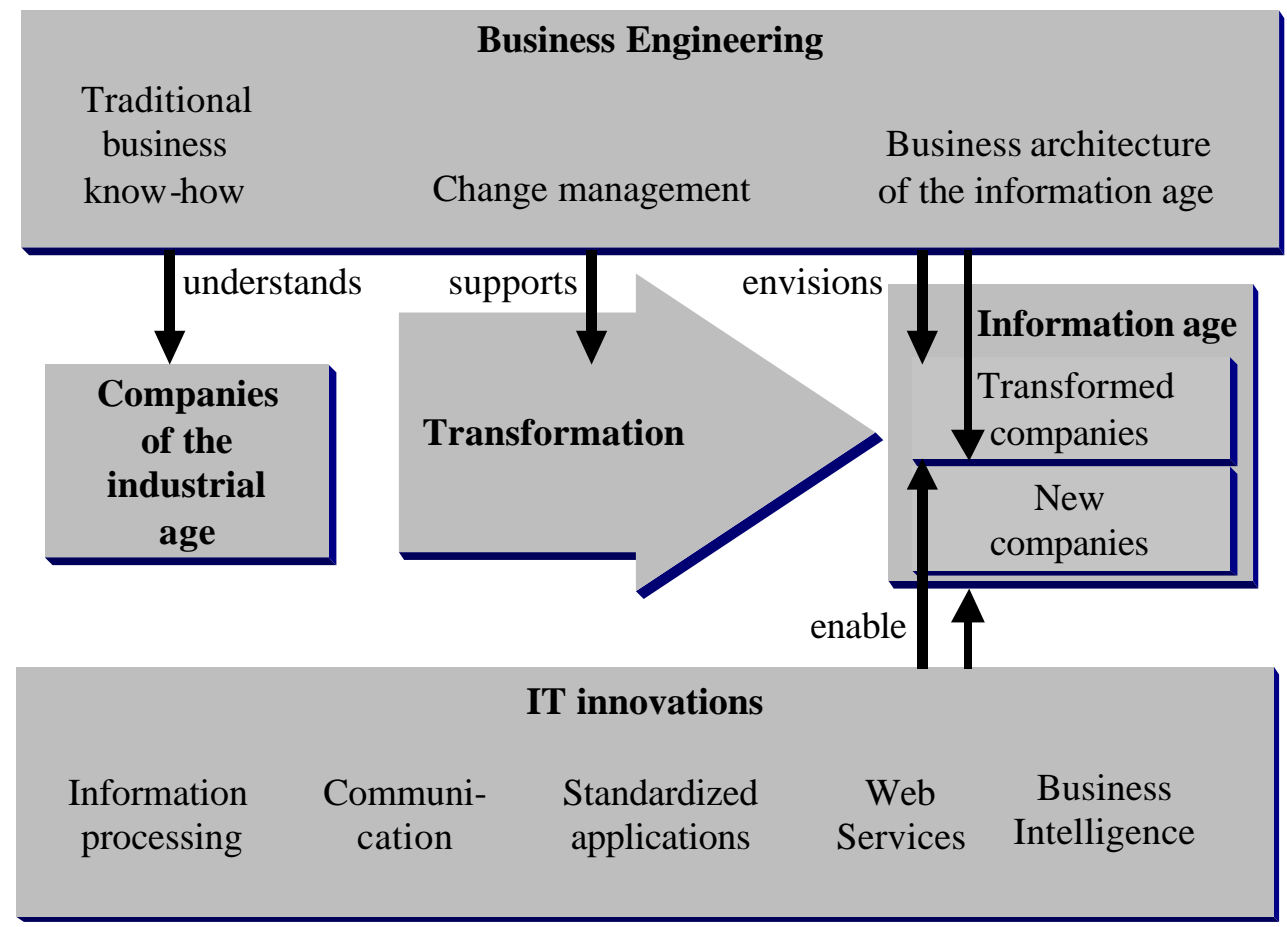

Figure 1: Transformation, IT, and Business Engineering. 


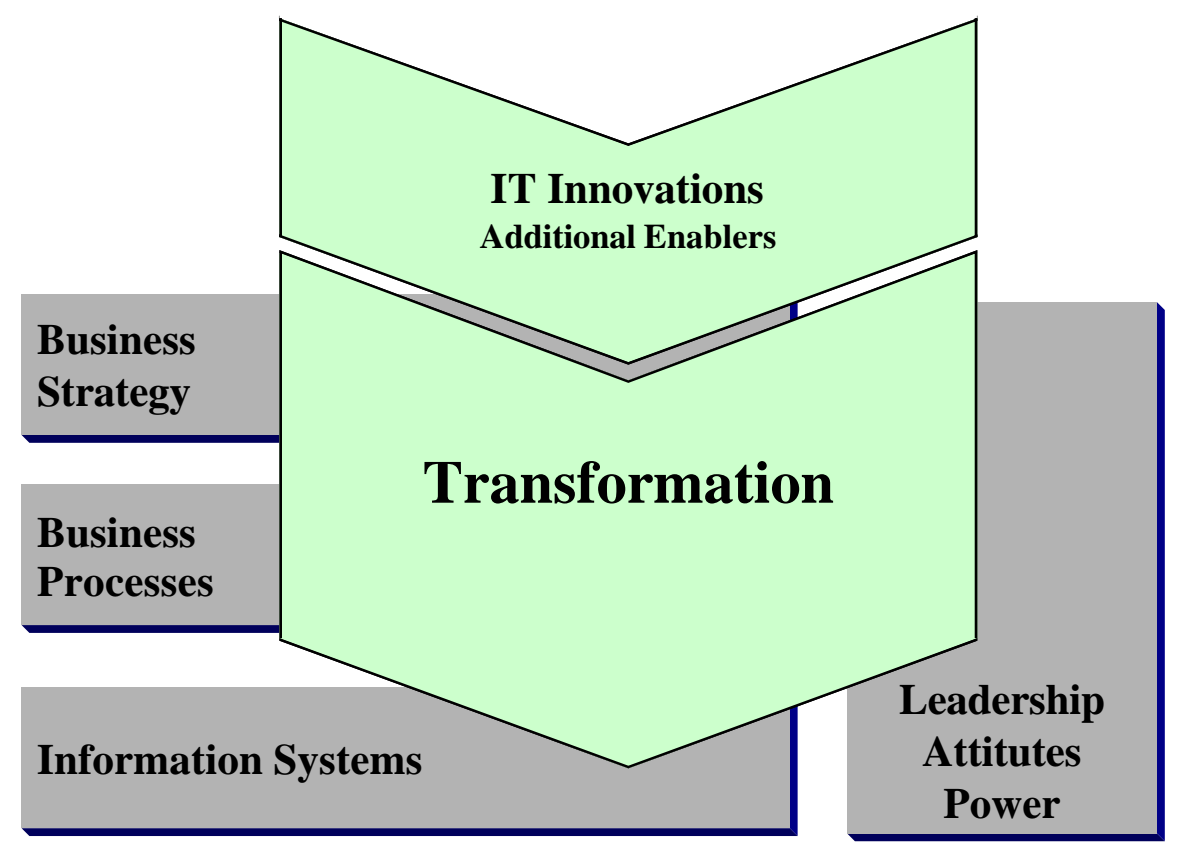

Figure 2: Business Engineering process.

these three levels, strong links to a 'soft' sector covering leadership, attitudes and power have to be considered (Winter, 2001).

\section{Program Layout and Curriculum}

In order to qualify professionals to holistically approach complex change problems in business, an innovative, cross-disciplinary layout for educating Business Engineering at the university level had to be developed. In the following, we start with describing the role model 'Business Engineer'. Based on that role model, general layout features of the developed program are derived. Finally, the most important components of the curriculum are summarized.

\section{Role Model}

Our role model for Business Engineers is based on James Martin's 'Enterprise Engineer'. His core qualifications (Martin, 1995)

- technical / management training

- business experience

- systems development experience

- understanding of human factors

imply the focal issues of the program: Besides mastering the Business Engineering methodology, Bus iness Engineers need to have a broad technical background (current IT trends and business potentials of IT innovations) and a business background (strategic management, process management). They should be able to (re-)design companies on the strategy level as well as on the process level and on the information systems level. With regard to transformation processes, they should take into account political issues as well as organizational development issues. With regard to human factors, they should be capable of change management and leadership in transforming organizations. 


\section{General Layout}

With the Business Engineering approach, we are addressing change projects involving potentially very large numbers of employees and high investment volumes. The average Business Engineer is an experienced professional with a university degree in management / business administration, computer science or engineering, at least 3-5 years post-degree work experience, and project management experience. A Business Engineering university program has therefore to be positioned as a post-graduate program, the most appropriate degree for Business Engineers being an Executive MBA degree.

We are developing methods and models to support professionals in practical problem situations. To allow for a direct, continuous exchange between work experience on the one hand and research and teaching on the other hand, these activities should happen simultaneously. We therefore need to offer the program as a part-time program to allow participating Business Engineers to maintain their careers and stay involved in suitable change projects.

If different knowledge areas are to be integrated (e.g. different perspectives of 'change'), a small faculty with shared vision and common background should work with students reflecting a broad range of different industries and majors. Hence students have to be selected very carefully based on their management and project experiences rather than on grades or standardized tests (e.g. GMAT). Instead of a formal assessment, structured interviews have been chosen to assess applicants.

Faculty should be involved in applied research projects rather than completely focus on teaching or pure academic research. First-hand experience in change projects outweighs didactic perfection as long as university standards are met. In addition to university faculty, experienced practitioners both from transforming companies and from IT vendors and change consultancies should be teaching.

Therefore an Executive MBA degree program was created that is open for management / business administration graduates as well as for graduates from other disciplines (e.g. computer science, engineering, economics, and psychology). The Executive MBA in Business Engineering program is offered as a part-time program. To guarantee an effective learning situation, two-week learning periods at the university alternate with six-week practice periods in which the students return to their jobs. For a curriculum that covers 20 weeks (100 days) of learning at the university, a total program duration of approximately 18 months is needed. Learning modules usually comprise six 75 minute segments on five days per week. Together with breaks, this adds up to a daily schedule from 8am through 6.30pm with many of the evenings used for high-profile guest speakers, group projects and / or work on the master thesis.

It is recommended that students stay assigned to an actual change project in their employing company and that they cover this project with their master thesis. In addition, the 'Business Engineering Center' as an Internet-based community platform is used as a common and continuous content / communications framework for the entire program duration.

\section{Curriculum}

The 20 learning weeks are organized in distinct modules that each focus on a specific aspect and / or level of Business Engineering or underlying disciplines, respectively. Initially, the entire program was developed independently from other Executive MBA programs and comprised one four-week and 14 one-week modules. Since selected modules of the Executive MBA in Business Engineering are identical with modules of other Executive MBA programs, a program structure comprising 'general' and 'specific' modules was adopted.

In contrast to other Executive MBA programs, the Executive MBA in Business Engineering addresses business administration graduates. As a consequence, it was necessary to let students that already hold a management / business administration degree opt out of selected general modules. 


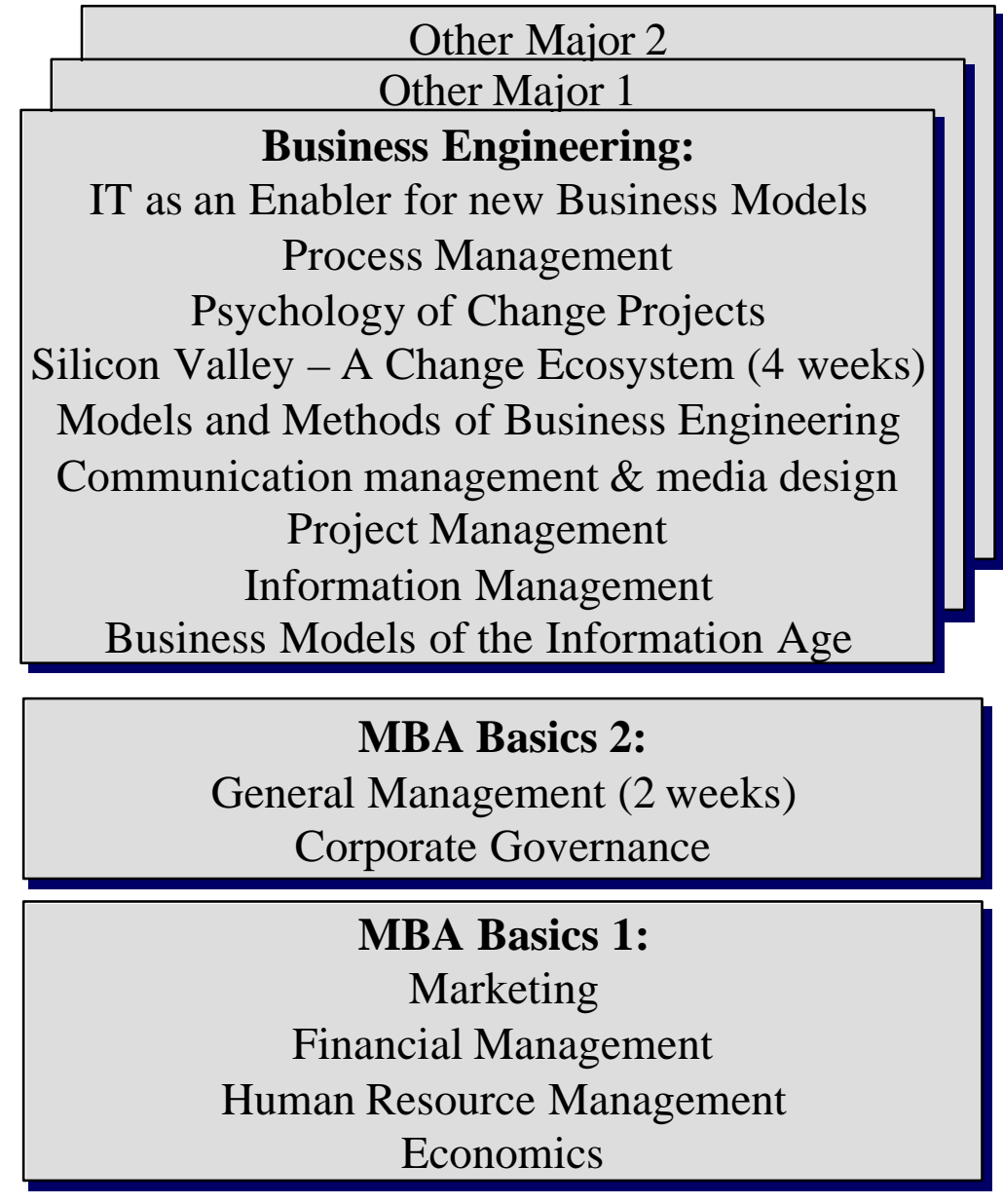

Figure 3: Learning modules.
Figure 3 illustrates a possible resulting program structure:

- MBA Basics 1 comprises four one-week modules that students already holding a management / business administration degree can opt out of. For all other Executive MBA students (including those from programs other than Business Engineering), these modules are compulsory.

- MBA Basics 2 comprises one two-week and one one-week module that have to be attended by all Executive MBA students.

- Business Engineering comprises nine modules (12 weeks) that are specific (and compulsory) for Executive MBA students in Business Engineering. In addition, every Executive MBA program includes a program specific kickoff week where the respective philosophy, the infrastructure and the way of learning are introduced.

The following subsections give an overview over core areas of the curriculum.

\section{Information systems and change}

The modules 'IT as an Enabler...', 'Methods and Models of Business Engineering', 'Information Management' and 'Business Models of the Information Age' constitute the information systems view on change.

Being potential enablers for new business models and reinvented processes, IT innovations and novel standardized software packages as well as appropriate information systems architectures are addressed. Also more technical topics like media convergence, platforms for electronic commerce, infrastructures for mobile work etc. are cove red. One week in the last quarter of the program is used to integrate all Business Engineering methods and models, thereby providing a holistic methodological view.

The final week 'Business Models of the Information Age' is used to work on all relevant aspects of a case holistically, thereby holistically covering change cases form different industries. Students' work is reviewed by board members of large companies.

\section{General management and change}

The modules 'General management', 'Corporate Governance' and 'Process Management' constitute the business administration disciplinary view on change. 
Being presented by renown management faculty, state-of-the-art concepts for shareholder value creation, network management, strategy development, transformation management, and organizational development (Gomez, Lauper, Probst, 1991; Gomez, Rüegg-Stürm, 1997; Müller-Stewens, 1997) are complemented by computer-based simulations and support tool demos (e.g. balanced scorecard). Special emphasis is given to process management and process optimization.

\section{Organizational psychology and change}

The modules 'Psychology of Change Projects' and portions of the modules 'Project Management', 'Communication Management...' and 'Silicon Valley...' constitute the communications and leadership view on change.

Coordinated by experienced executives, students get in touch with tools and concepts for business case planning, project management, and financial aspects of change projects. Less theoretical, but valuable personal experience can be gained in a one-week outdoor module that takes place in the mountains. The goal of this week is to have personal encounters with uncertainties, conflicts, group dynamics, and other challenges for leadership in transforming companies.

\section{Infrastructure, culture, and change}

The module 'Silicon Valley - A Change Ecosystem' focuses on the infrastructure and cultural view on change.

Switzerland and Germany may not be the best places to study rapid and radical business transformations. Although considerable attention is paid to organizational and personal agility also in Europe, the most comprehensive 'ecosystem' for IT-enabled change is Silicon Valley. This was true in the peak of the bubble economy and is still true in times of sharp economic downturn. We cooperate with a university in the center of Silicon Valley to offer a four-week in depth experience of the 'Silicon Valley way of change'. While formal sessions provide theoretical concepts for entrepreneurship, innovation management, creativity support, and cultural alignment, various high tech company visits allow students to get in touch with best practices and the people behind successful transformations.

\section{Experience and Future Directions}

Initially (from 1998) bearing the name Master of Business Engineering and subseque ntly Executive Master of Business Engineering, the program was renamed Executive MBA in Business Engineering in 2001. Total tuition fees for 20 weeks, thesis supervision and Intranet access are currently $60000 \mathrm{CHF}$ (ca. 41000 USD as of July 2002) plus travel and accommodation costs (see www.mbe.unisg.ch).

\section{Applications and Participants}

The program attracts between 60 and 110 applications per year. After one class with 45 students was started in 1998, 1999 and 2000, two classes with together 85 students were started in 2001. On the average, employers contribute $50 \%$ to the tuition fees, the other expenses and the absences. Between $75 \%$ and $90 \%$ of the students of this mainly German language program work in Switzerland, the remainder mostly in Germany.

Figure 4 exhibits the graduation disciplines of the participants in the first six classes. Surprisingly $50 \%$ of the participants are management / business administration graduates which is very unusual for an Executive MBA program. 


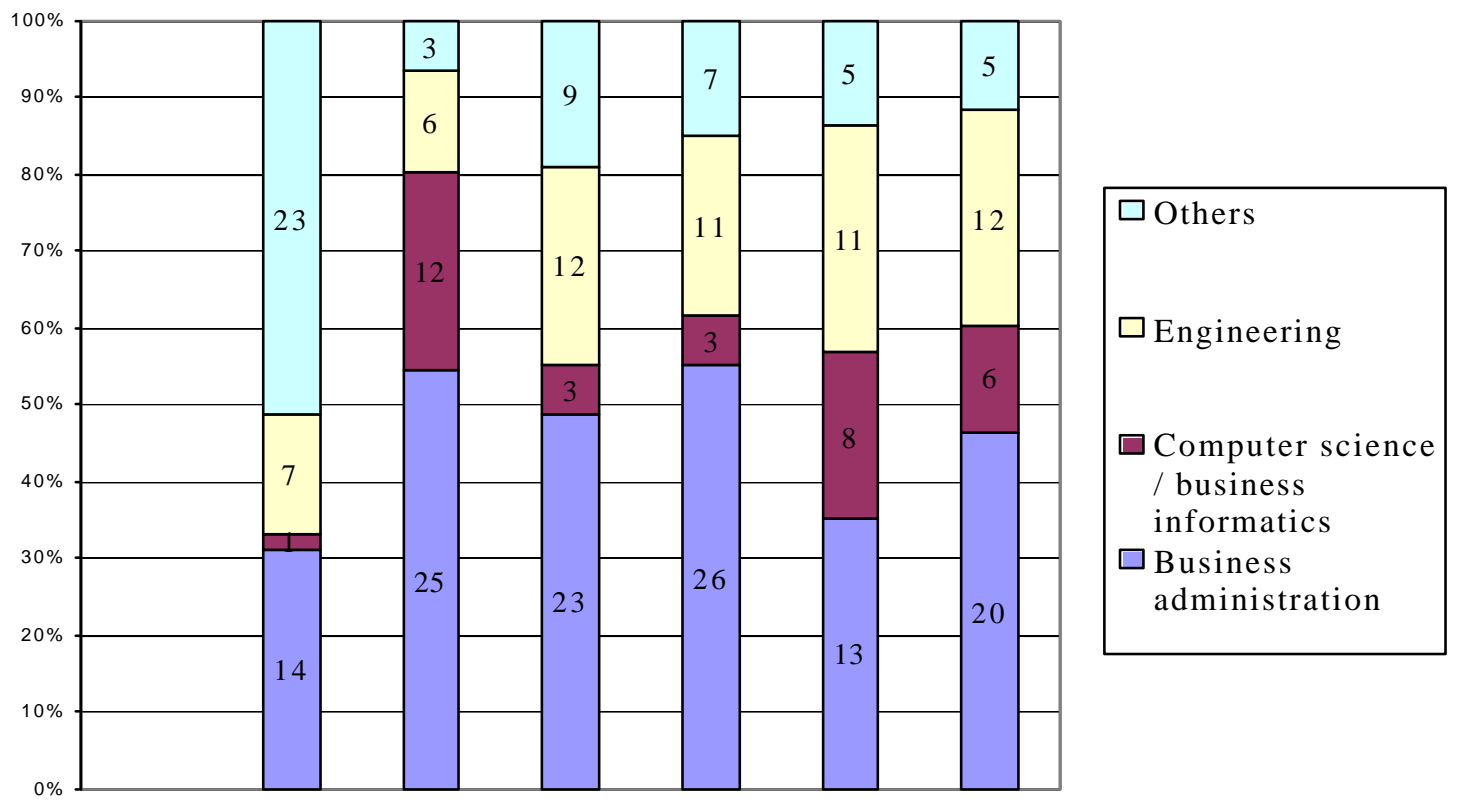

\section{Figure 4: Graduation discipline of program participants.}

Figure 5 exhibits the industries where the participants were employed (at the time they were admitted to the program) for the first six classes. Banking and other financial services supply around $40 \%$ of the participants which is no surprise due to the extent of restructuring in these industries and their importance for Switzerland and Germany.

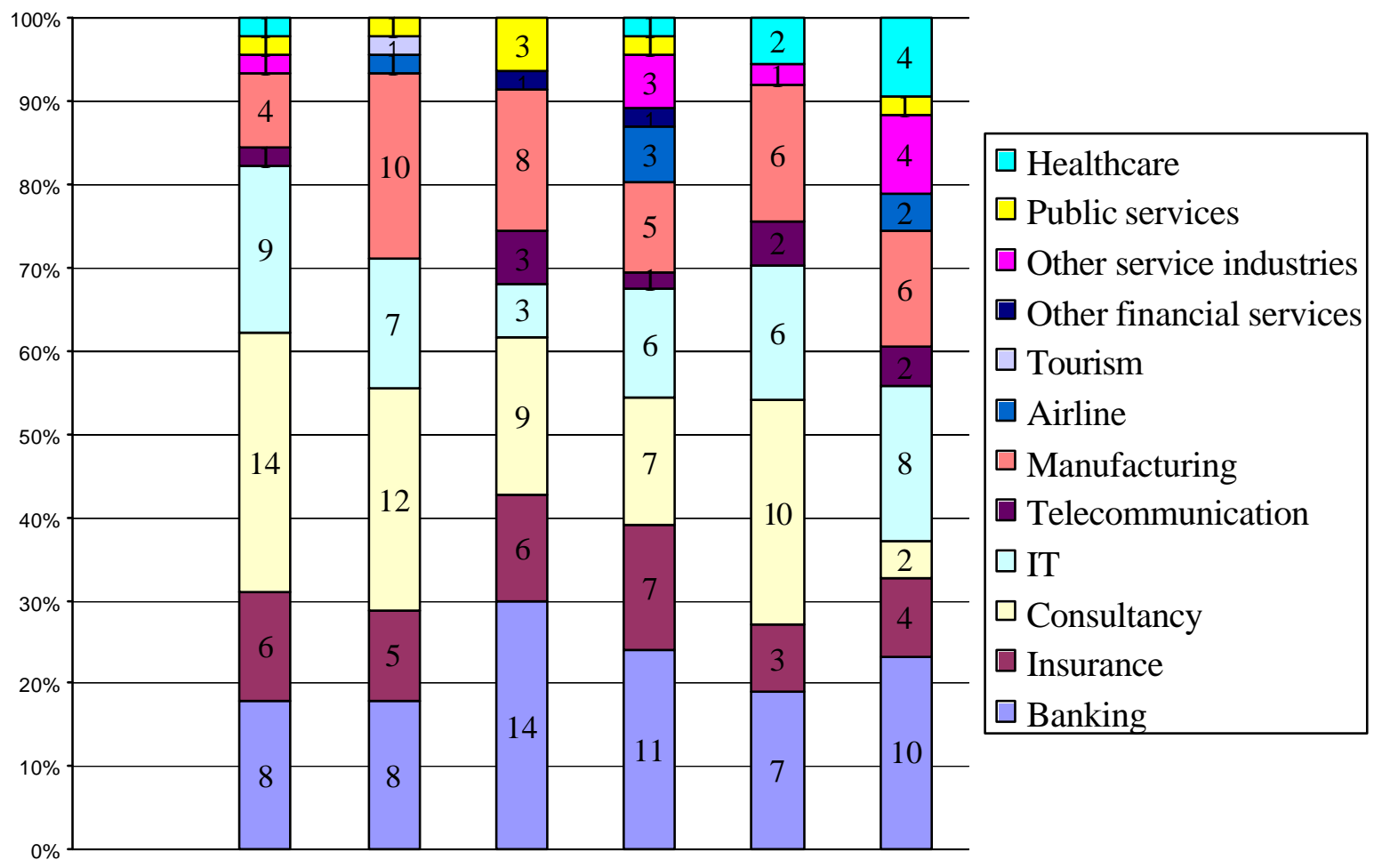

Figure 5: Industry of program participants. 
Only few participants are self-employed. During the program, a large number of students change their jobs, most of them in order to exploit new career opportunities as Business Engineers within or outside their company, some to start their own consulting business.

\section{Curriculum Developments}

All modules are being extensively evaluated by students and by faculty. As a consequence, in the second year a one-week kickoff module has been introduced, and the project management module which initially was a two-week module has been shortened to one week in order to create an additional one-week module for the analysis of change cases.

In a second curriculum adjustment after another two years, common modules with the Executive MBA in General Management program were identified. For every 'general management' module, one alternative module was offered in order to make the program more attractive for students that already held management / business administration degrees. During that phase, additional modules like technology and innovation management, public relations, international management, or international business law were offered. The program options, however, led to frequent changes in learning groups and made it difficult to maintain the Business Engineer profile throughout the program. As a consequence, the curriculum structure presented in the curriculum subsection is currently being developed.

\section{Outlook}

The combination of contributions of disciplines like management / business administration, computer science and organizational psychology under a change focus is an innovative approach whose sound theoretical foundation is still a work in progress. We contribute to that progress in two different ways. On the one hand, the 'Business Engineering Center', a platform that allows a structured access to a vast amount of Business Engineering knowledge, is intended to support a growing Business Engineering community, thereby gaining empirical feedback on the proposed methods and models. On the other hand, various large research projects ('competence centers', e.g. for business networking, customer relationship management, application integration management, telematics, mobile commerce, etc.) bring together companies and researchers for a permanent enhancement of Business Engineering methodology. Therefore the Executive MBA in Business Engineering approach seems to us not only to be innovative with regard to its cross-disciplinary nature and its attraction to management / business administration graduates. Moreover, the tight integration of part-time executive education and applied research creates relevant results in an active network of professionals and academics.

\section{References}

Brinkke mper, S., Lyytinen, K., Welke, R. (1996). Method Engineering. London: Chapman \& Hall.

Davenport, P. H. (1993). Process Innovation: Reengineering Work through Information Technology. Boston: Harvard Business School Press.

Evans, P., Wurster, T.S. (1999). Blown to Bits - How the new Economics of Information transforms Strategy. Boston: Harvard Business School Press.

Gomez, P., Lauper, P., Probst, F. (1991). Networking Thinking in Strategic Management. Basel: Ciba Geigy.

Gomez, P., Rüegg-Stürm, J. (1997). On the Essence, Emergence and Effects of Visions: Some Cautions. Corporate Transformation (Sinatra, A. ed.), 69-93, Dordrecht: Kluwer.

Hagel III, J., Singer, M. (1999). Net Worth - Shaping Markets When Customers Make the Rules. Boston: Harvard Business School Press.

Kelly, K. (1998). New Rules for the new Economy - 10 radical Strategies for a connected World. New York: Viking Penguin.

Martin, J. (1995). The Enterprise Engineer, Computerworld, 18.09.1995. 
Müller-Stewens, G. (1997). Fundamental change in highly complex organizations. Corporate Transformation (Sinatra, A., ed.), 132-152, Dordrecht: Kluwer.

Österle, H. (1995). Business in the Information Age - Heading for New Processes. New York: Springer.

Österle, H., Fleisch, E., Alt, R. (2000). Business Networking - Shaping Enterprise Relationships on the Internet. New York: Springer.

Österle, H., Winter, R. (2000). Business Engineering - Auf dem Weg zum Unternehmen des Informationszeitalters. Berlin: Springer.

Team Denzler (2002). Executive MBA: Zukunft des NDU St.Gallen. Internal Report, University of St. Gallen.

Winter, R. (2001). Working for e-Business - The Business Engineering Approach. International Journal of Business Studies, 9, 1, 101-117.

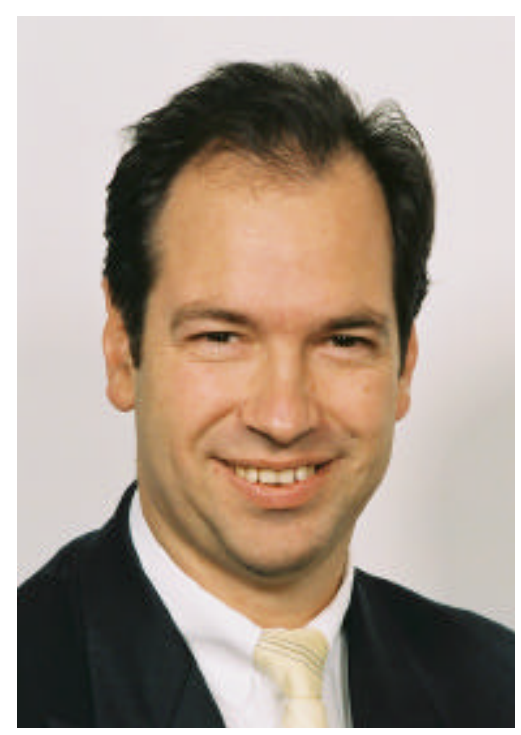

\section{Biography}

Prof. Dr. Robert Winter is director of the Institute of Information Management, University of St. Gallen (HSG), Switzerland, and director of HSG's Executive MBA program in Business Engineering. He received Master degrees in Business Administration (1984) and Business Education (1986) from Goethe University Frankfurt, Germany. As a research assistant with Goethe University from 1984 through 1994, he received a doctorate in social sciences for his work in the field of multi-stage production planning (1989) and venia legendi for his work on formal semantics of conceptual information systems design (1994).

His research interests include business engineering methods and models, information systems architectures / architecture management, and integration technologies / integration management (particularly data warehousing and enterprise application integration). 